\title{
The Unexplored Parental Age Gap in an Era of Fertility Postponement
}

\author{
Christian Dudel I dudel@demogr.mpg.de \\ Yen-hsin Alice Cheng I aliceyh@gate.sinica.edu.tw \\ Sebastian Klüsener I sebastian.kluesener@bib.bund.de
}

This working paper has been approved for release by: Peter Eibich (eibich@demogr.mpg.de),

Deputy Head of the Laboratory of Labor Demography.

(c) Copyright is held by the authors. 


\title{
The Unexplored Parental Age Gap in an Era of Fertility Postponement
}

\author{
Christian Dudel (1), Yen-hsin Alice Cheng (2), Sebastian Klüsener (3)
}

1: Corresponding author; Max Planck Institute for Demographic Research, Germany; email: dudel@demogr.mpg.de; address: Max Planck Institute for Demographic Research, Konrad-ZuseStr. 1, 18057 Rostock, Germany;

2: Institute of Sociology, Academia Sinica, Taiwan; email: aliceyh@gate.sinica.edu.tw

3: Federal Institute for Population Research, Germany; email: sebastian.kluesener@bib.bund.de

\begin{abstract}
Fertility postponement is usually analyzed separately for women and men. Here, we present the first comparative study of fertility postponement of men and women covering 15 high-income countries. As expected, general trends in mean ages at childbirth are very similar among men and women. However, these similarities hide sharp gender differences in unexplored relationships between maternal and paternal ages at childbirth, which we uncover by deriving the mean age differences between the parents conditional on the maternal or paternal age. Between ages 20 and 40, the age differences become smaller for mothers in a strikingly linear manner; and larger for fathers. In recent decades, this linear relationship shifted, with younger mothers increasingly partnering with older fathers, and older mothers increasingly partnering with similar-aged fathers. Fathers, on the other hand, experienced decreasing age differences at all ages. We discuss the implications of our findings for fertility postponement and gender equality debates.
\end{abstract}




\section{Is postponement contributing to gender equality?}

Contemporary family changes have resulted in shifting patterns of union formation, such as rising cohabitation rates, the declining prevalence of educational hypergamy (Esteve, GarcíaRomán and Permanyer 2012), later and fewer marriages, and later childbearing and fewer childbirths (Lesthaeghe 2014). Of these family behaviors, assortative mating patterns by education, ethnicity, and social status have been studied most thoroughly because of their implications for social inequalities and mobility (Blossfeld 2009, Blossfeld and Buchholz 2009, Kalmijn 2013, Nitsche et al. 2018, Qian and Lichter 2007). Existing research on marriage patterns by age since the beginning of the $20^{\text {th }}$ century has shown that there has been a long-term decline in extreme age differences between husbands and wives, and that age-homogamous unions have become more common in various contexts (Esteve, Cortina, and Cabré 2009, Kolk 2015, Van Poppel et al. 2001). These shifts have resulted in a general decline in the age differences between spouses in a number of developed countries.

Parental age differences at childbirth have been studied less frequently than marital age differences, even though the former have social meanings in couple dynamics, and are relevant to recent discussions on fertility postponement. A large age difference between parents - and particularly when the father is much older than the mother - is often considered an indicator of gender inequality in power relations (Presser 1975, Pyke and Adams 2010). Thus, shifting age differences among parents is likely to signify evolving gender power relations in societies in which the status of women has been advancing rapidly (Kolk 2015, Dudel and Klüsener 2019c). In these processes, changes in age differences can be both a source and an outcome of changes in power relations. In addition, past research has indicated that contemporary delays in family formation are often associated with declining spousal age differences over time (Esteve, Cortina, and Cabré 2009; Kolk 2015; Van Poppel et al. 2001). Therefore, it might be interesting to compare shifts in parental age pairings in recent decades with family changes in different countries. However, the much-studied data series on the age pairings of spouses at marriage are becoming less relevant for understanding age differences among parents, as cohabitation is becoming more prevalent in many developed nations, and many of these couples are having children (Perelli-Harris et al. 2010, Billari and Liefbroer 2010). 
Among the mechanisms that might be affecting parental age differences are differentials in the fertility postponement patterns of women and men. For instance, if postponement was more pronounced for women than men, then the age differentials might decrease. This tendency could be driven by trends in female employment and enrolment in tertiary education, which have been increasing steadily in many high-income countries, and are seen as indicating a shift toward gender equality (Goldscheider et al. 2015, Grow et al. 2017). Thus, fertility postponement is likely to occur as power relations change. However, while delayed motherhood has received considerable attention in the literature (Kohler et al. 2002; Sobotka 2004, Fox et al. 2018), there is far less research on fertility postponement among men, or on parental age differences.

In this paper, we make an important contribution to the literature by providing the first systematic cross-country comparative investigation of the understudied issue of fertility postponement among men and women and parental age differences at childbirth. We analyze data from 15 high-income countries in Europe, North America, and East Asia over a time span of several decades, with the longest time series starting in the late 1960s. Our analysis is based on high-quality vital registration data from all 15 countries. The results of our investigation of postponement trends show that mean ages at childbirth have evolved very similar for men and women. However, these similarities hide sharp gender differences in previously unexplored relationships between maternal and paternal ages at childbirth. To our knowledge, we are the first to detect and analyze these systematic relationships. We uncover these relationships by deriving the mean age differences between the parents of a child, conditional on the maternal or paternal age; e.g., for each maternal age, we calculate the mean difference between that age and the father's age. We show that in all of the studied countries between ages 20 and 40, there is an almost linear relationship between the mother's or the father's age and the parental age difference. The age difference between the mother and the father is, on average, largest when the mother is aged 20, and is smallest when the mother is aged 40. Among fathers, the opposite pattern is observed. In recent decades, this almost linear relationship has tilted among mothers, as younger mothers have become increasingly likely to partner with older fathers, and older mothers have become increasingly likely to partner with similar-aged men. Among fathers, on the other hand, we observe a downward shift, as the age differences between fathers and mothers 
have been decreasing at all ages. Our findings are consistent with the idea that fertility postponement is accompanied by changes in couples' power relations.

\section{Data and methods}

\section{Data}

Our analyses are based on unique vital registration data covering 316,756,697 live births in 15 high-income countries. The countries (in alphabetical order) and years we cover, and the total number of births per country, are as follows:
○ Canada, 1974-2016: 15,802,285
○ Hungary, 1970-2015: 5,531,052
○ Denmark, 1986-2015: 1,899,172
○ Italy, 1999-2015: 8,743,545
○ England and Wales, 1982-2016:
○ Japan, 2009-2015: 6,262,714
$23,345,243$
○ Poland, 1986-2015: 12,735,720
○ Estonia, 1989-2015: 391,541
- Spain, 1975-2014: 18,572,616
○ France, 1998-2013: 1,741,444
○ Sweden, 1968-2015: 5,010,338
○ Finland, 1987-2015: 12,507,805
○ Taiwan, 1998-2016: 3,820,183
○ Germany, 1991-2013: 20,905,142
○ USA, 1969-2015: 179,487,897

In total, there are 686 country-year combinations. The data were obtained from national statistical offices; except in the United States, where the data were provided by the National Bureau of Economic Research. The raw data are similar to the data discussed in Dudel and Klüsener (2019), and we refer to their documentations for a detailed description. An overview of the most important aspects and features of these data with respect to our analysis is also provided in the appendix. In most country datasets, the age of the father is missing for some births. We address this issue by adopting the so-called conditional approach (Dudel \& Klüsener 2018b) to impute missing values; see the appendix for details.

\section{Methods}

For each country, we show trends in the mean age at childbirth for men and women, which we use as an indicator of fertility postponement. To assess parental age differences, we calculate the average difference between the paternal age and the maternal age at childbirth for a given year in a country. That is, for each birth, we take the paternal age minus the 
maternal age, and then calculate the mean. If, for example, the average age difference has a positive value of 3.5 years, then fathers are, on average, 3.5 years older than mothers. If, by contrast, the age difference has a negative value of, for example, -2 years, then fathers are, on average, two years younger than mothers.

We condition the parental age difference either on the maternal age or on the paternal age. When conditioning on the maternal age, we study how the age difference between mother and father is affected by the maternal age. For instance, the parental age difference may be bigger (or smaller) for births to younger mothers than for births to older mothers.

Explorative analyses demonstrated that the age differences conditional on the maternal or the paternal age have almost a linear relationship in most countries. We thus decided to model this relationship using linear regression. As the dependent variable, we take the conditional average age difference of a given year and country, and use the corresponding maternal age minus 20 as the explanatory variable (see below). Formally, if $\mathrm{X}$ denotes the age of the mother and $\mathrm{Y}$ denotes the age of the father, then analyses conditioning on the age of the mother use the values of $\mathrm{M}(\mathrm{Y}-\mathrm{X} \mid \mathrm{X})$ as a dependent variable, where $\mathrm{M}$ denotes the arithmetic mean, and $\mathrm{X}-20$ is used as an explanatory variable: $\mathrm{M}(\mathrm{Y}-\mathrm{X} \mid \mathrm{X})=\alpha_{\mathrm{x}}+\beta_{\mathrm{X}}(\mathrm{X}-$ $20)+\varepsilon$, where $\varepsilon$ is an error term. We run these regressions for each country-year combination, such that for each country and year, we have an intercept $\alpha_{\mathrm{x}}$ and a slope $\beta_{\mathrm{x}}$.

When running regressions conditioned on the age of the mother, we restrict $X$ to be in the range of 20 to 40 . This is because at lower and at higher ages, the numbers of births are low in many countries and years. This restriction, in combination with using $\mathrm{X}-20$ as explanatory variable, allows for a simple interpretation of the intercept $\alpha_{\mathrm{x}}$ : namely, that it captures the average age difference between mother and father when the mother is 20 years old; i.e., when the mother is young. The slope $\beta_{\mathrm{x}}$ captures heterogeneity across the age range. The larger the absolute value of $\beta_{x}$ is, the larger the difference between younger and older mothers is. If $\beta_{\mathrm{x}}$ is negative, the age differences are decreasing with the age of the mother, and older mothers are exhibiting smaller age differences; while the opposite is the case if $\beta_{\mathrm{x}}$ is positive. 
We also run regressions conditioning on the age of the father, which work in a similar way. When conditioning on the age of the father, we use $\mathrm{Y}$ as an explanatory variable; i.e., $\mathrm{M}(\mathrm{Y}-\mathrm{X} \mid \mathrm{Y})=\alpha_{\mathrm{Y}}+\beta_{\mathrm{Y}}(\mathrm{Y}-20)+\varepsilon$. We use an age range of 20 to 45 . The age range is wider for men than for women because men tend to have children at somewhat higher ages than women.

\section{Results}

\section{Similar trends in mean age at birth for men and women}

Figure 1 shows trends in fertility postponement among men and women in a selection of the countries we cover; results for all countries are available in the appendix, and are very similar to the findings shown in Figure 1. While the mean ages at childbirth differ considerably across countries and over time, the trends have been rather consistent for both men and women, at least since the 1990s. Specifically, we show that in all 15 countries the mean age at childbirth increased steadily, and there have been strong postponement trends among both men and women. The trends for men have generally run parallel to the trends for women, with men delaying childbearing to roughly the same extent as women. For instance, in Sweden, the mean age at childbirth for women increased 4.5 years between 1968 and 2015, from 26.3 years to 30.8 years; while for Swedish men, the mean age at childbirth increased 4.3 years over the same period, from 29.4 years in 1968 to 33.7 in 2015. The trends for men and women in most of the other studied countries are similar to those in Sweden. Generally, the correlation between the mean age at childbirth for women and the mean age at childbirth for men is close to one. Trends in the (unconditional) average age difference between mother and father - which can be calculated from the results in Figure 1 as the difference in the mean age at childbirth between men and women - are shown and discussed in the appendix. 
Figure 1. Trends in the mean age at childbirth for men (dashed line) and women (solid line).
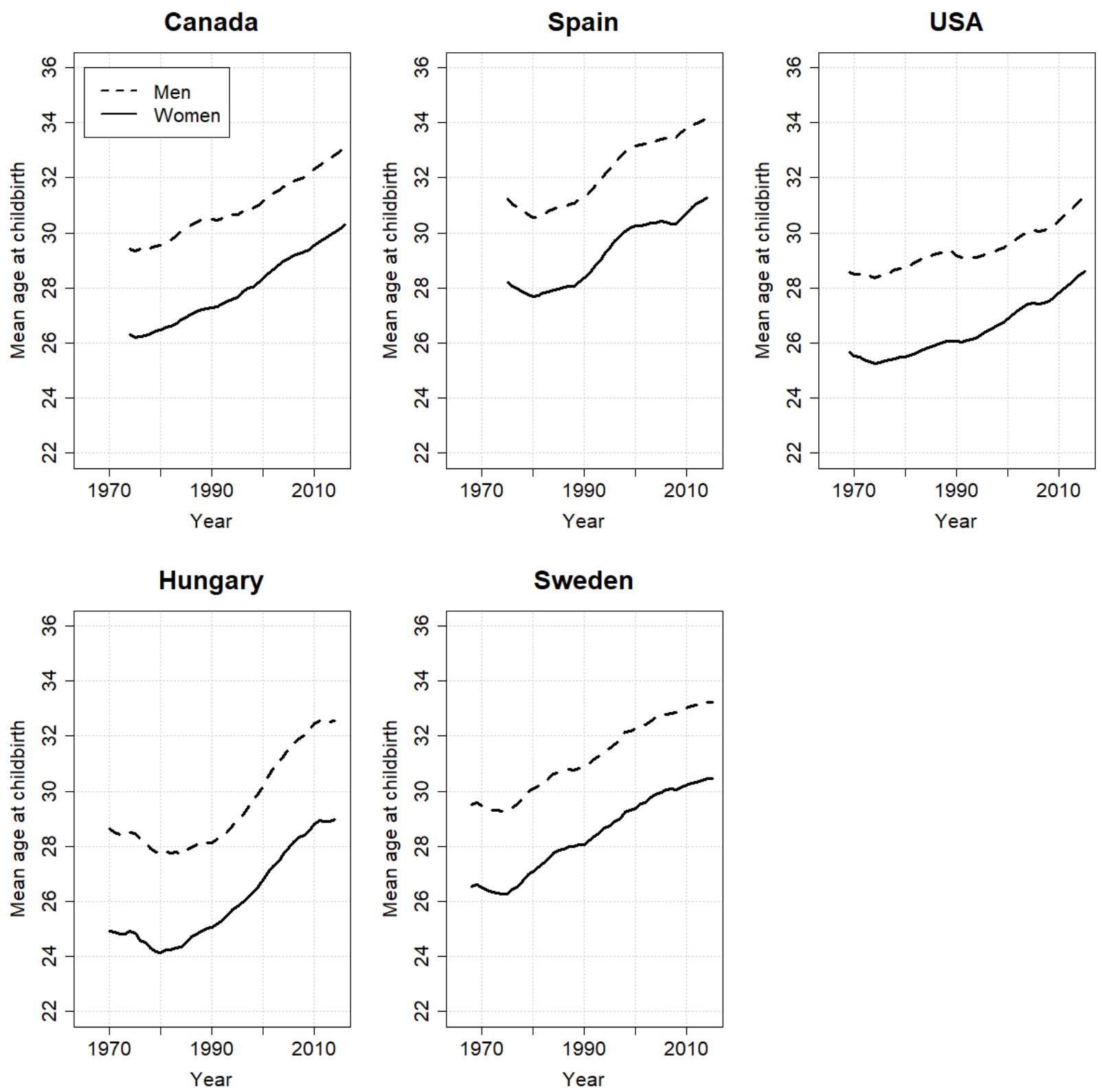

Source: Official Statistical Data, NBER (USA), own calculations 


\section{Conditional age differences vary substantially for men and women}

Figure 2 presents the results of our regression approach conditional on maternal age, while Figure 3 presents the results of our regression approach conditional on paternal age. Both figures show findings from selected countries for which we have data for 1975 (Canada, Spain, USA, Hungary, Sweden), and for around 40 years later (2014, 2015 or 2016, depending on which year is the last year available for a specific country). In these figures, the gray lines depict the patterns observed in the data, while the red lines show the estimated linear relationship, as described in the previous section. The solid lines show the results for 1975, and the dashed lines display the results for the mid-2010s. As the regression estimates closely follow the data, we will focus on them for our interpretation. For instance, the upper-left panel of Figure 2 shows that in Canada in 1975, the average parental age difference was around three years for mothers aged 20, and was less than two years for mothers aged 40. In 2015, the respective values were four years (mothers aged 20) and 1.5 years (mothers aged 40 ).

When we compare the results for countries shown in Figure 2, we see some heterogeneity, but also consistent patterns. For 1975, the regression lines are rather similar for all countries. This is remarkable considering that at that time, the economic and political situations in these countries were very different. The relationship is negative, which indicates that the mean parental age differences were smaller among older mothers. The slopes vary between -0.06 years and -0.17 years.

Most importantly, the results in the mid-2010s are more diverse. However, in all of the countries, the intercept of the regression lines is higher in the mid-2010s compared to 1975 , and the slopes are steeper. Thus, across the countries, the average age difference increased

for young mothers and decreased for older mothers. This, in turn, implies that the heterogeneity across the age range of mothers also increased. 
Figure 2. Mean spousal age differences at childbirth by mother's age, mid-1970s vs. mid$2010 \mathrm{~s}$
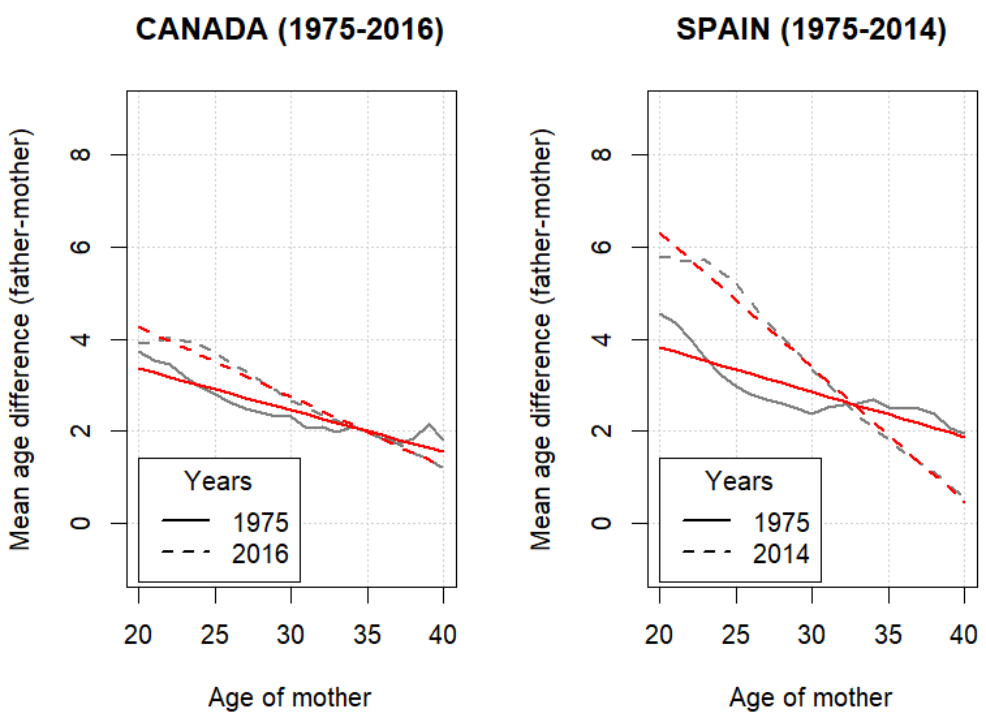

USA (1975-2015)

HUNGARY (1975-2015)

SWEDEN (1975-2015)
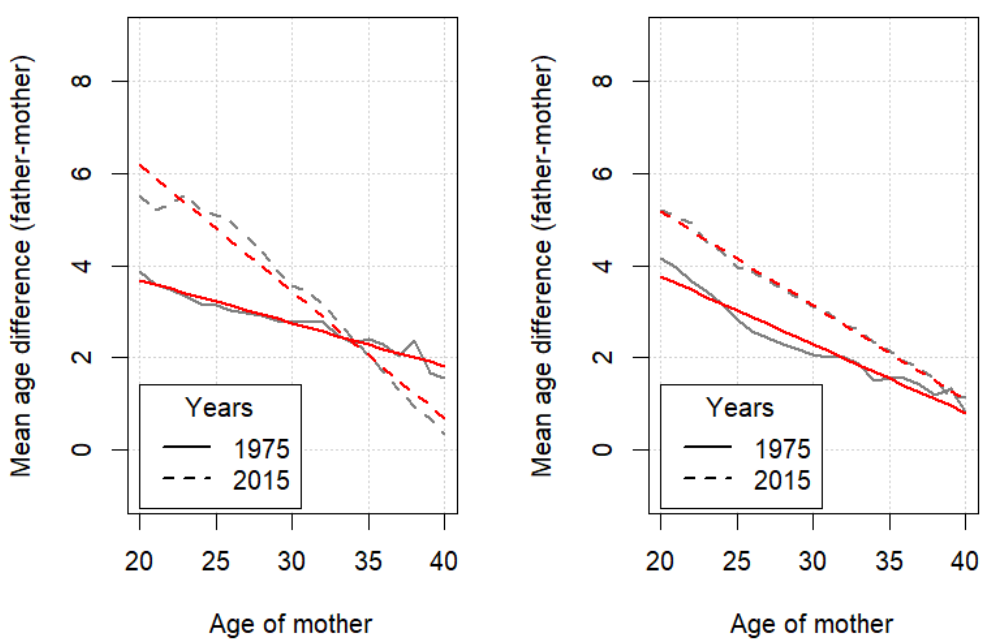

Note: Solid lines for 1975 and dashed lines for 2015. Gray lines are observed values and red lines are fitted regression lines.

Source: Official Statistical Data, NBER (USA), own calculations 
Figure 3. Mean partner age differences at childbirth by father's age, 1975-2015
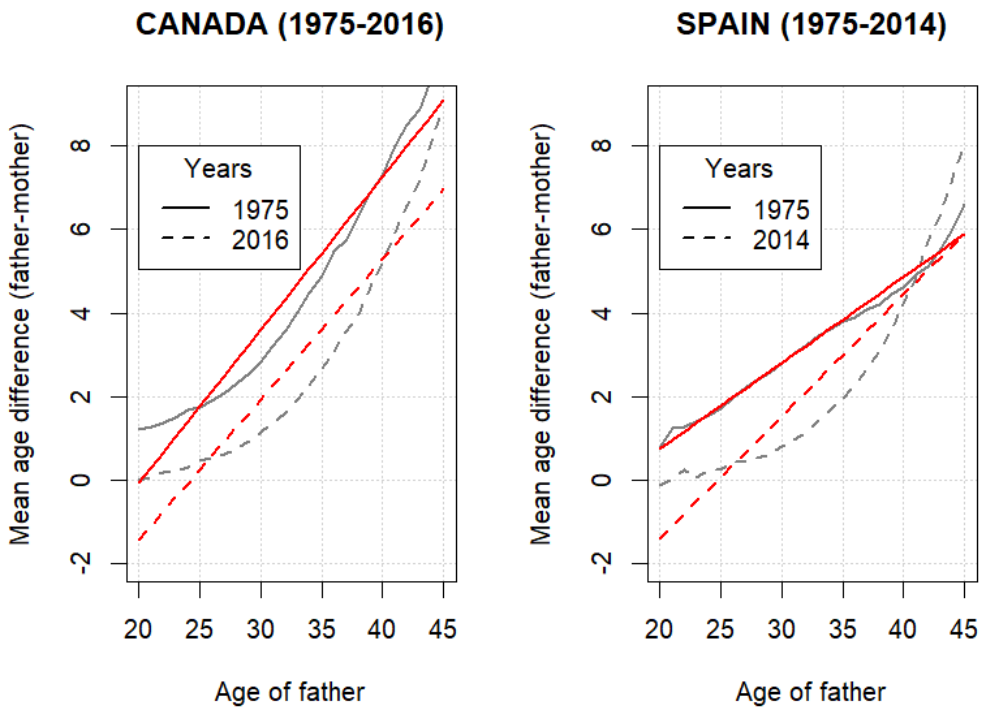

USA (1975-2015)
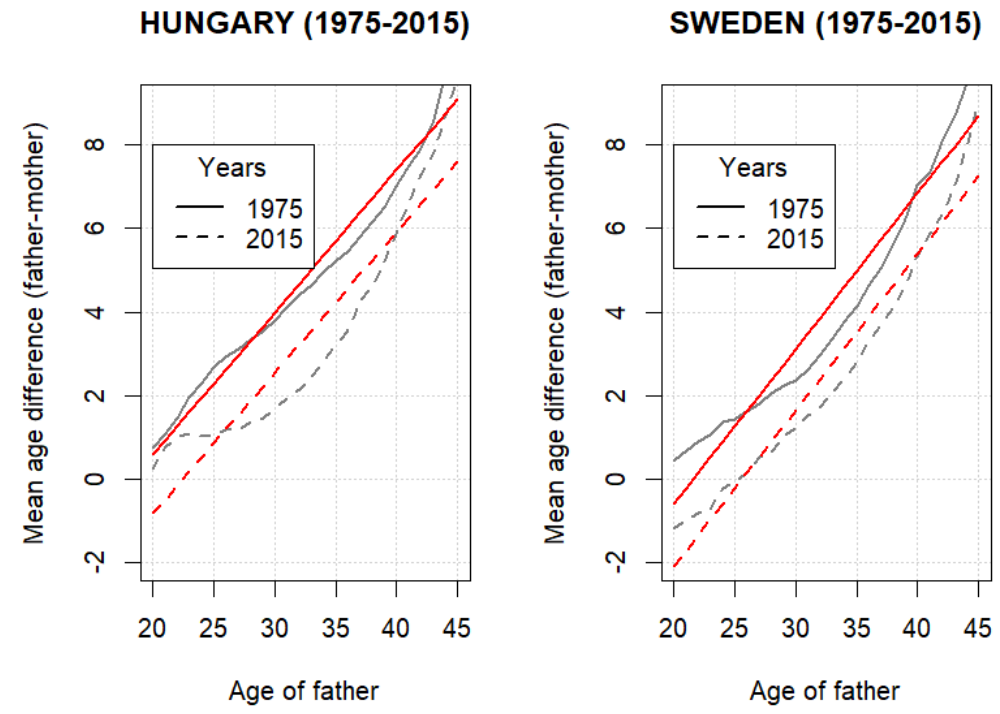

Note: Solid lines for 1975 and dashed lines for 2015. Gray lines are observed values and colored lines are fitted regression lines.

Source: Official Statistical Data, NBER (USA), own calculations 
We now turn to Figure 3, which shows patterns conditional on paternal age. As before, the age difference was calculated by subtracting the age of the mother from the age of the father. This implies that in order to obtain the mean age of the mother, one has to subtract the age difference from the paternal age. The estimated slopes are positive, which shows that among fathers, the parental age differences are increasing with age; i.e., that older fathers tend to have children with comparatively young mothers. The intercept is around or even below zero, which indicates that the age differences are small for young fathers.

The trends we observe for men are quite consistent over time. In 1975, all of the countries apart from Spain display very similar slopes. Over time, the slope for Spain is becoming more similar to the slopes of the other countries, and all of the countries show a decrease in the intercept, which indicates that the age differences were decreasing across all paternal ages.

\section{Conditional age differences: General patterns}

In Figure 4, we provide a summary graph of all of the intercepts and slopes for both mothers and fathers, and for all countries and years, covering all 686 country-year combinations. Earlier years are shown in purple (1960s), and recent years are shown in blue (2010s). The color gradient for the years in-between illustrates how the trends evolved over time.

Figure 4 demonstrates that the findings for the five countries described above are part of a larger, more general, and remarkable consistent pattern. For women, nearly all of the slopeintercept combinations fall along a single line, with the intercepts increasing, and the slopes decreasing and becoming steeper over time. Thus, the parental age differences increased for younger mothers and decreased for older mothers; and heterogeneity across the age range increased. The slopes for men show less variation than the slopes for women. Over time, these slopes are either staying constant or they are becoming steeper. Meanwhile, the intercepts for men generally decrease over time. Thus, from the perspective of fathers, parental age differences have generally been declining, but there has also been a rather stable pattern of older fathers tending to have children with much younger mothers. 
Figure 4. Trajectories of changes in age differences at childbirth across time for all countries

\section{Coefficients of all countries and years}

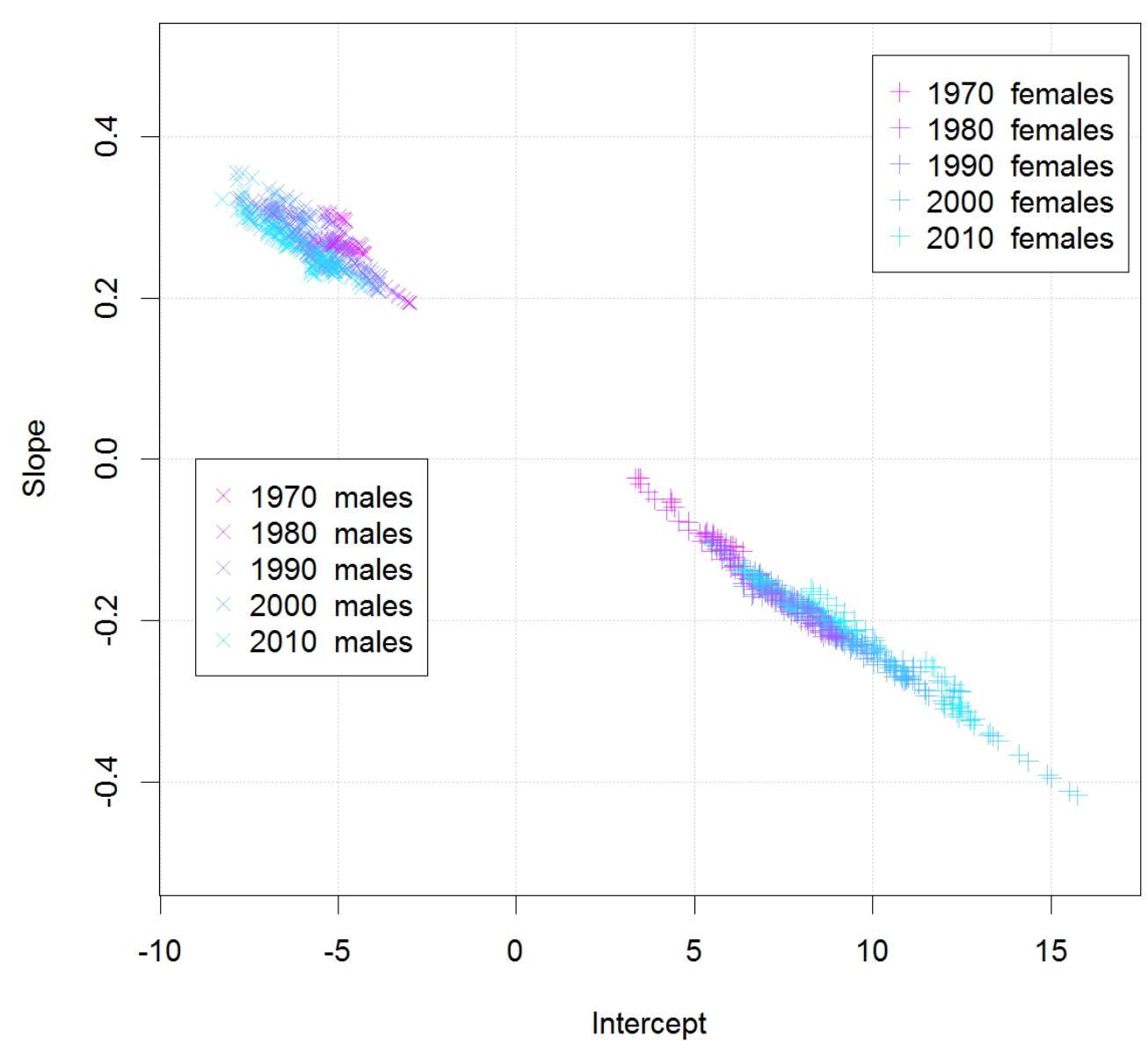

Source: Official Statistical Data, NBER (USA), own calculations

\section{Implications}

This study has contextualized changing parental age differences within the global trend of fertility postponement. Conditioning parental age differences on the age of one parent, and using a regression approach, we found results that are consistent with both the literature on partnering patterns and gender equality. On the one hand, our findings are in line with 
observations that men generally prefer younger partners as they become older, while women's age preferences for their partners are more heterogeneous (Skopek, Schmitz, and Blossfeld 2011). On the other hand, consistent with the literature on gender equality, we also showed that the shift in parental age differences over time has been gendered. For women, this shift has led to greater heterogeneity across ages, such that the parental age differences among younger and older mothers differ more today than in the past. Among fathers, on the other hand, the parental age differences have declined, independent of the age at which they had a(nother) child. These observations are in line with existing findings that the fertility changes by social status or by age that have occurred in recent decades have been much larger for women than for men (see Jalovaara et al. 2018). A possible explanation for this is that women's socioeconomic status has been changing more rapidly. However, while it is clear that the patterns of parental age gaps are gendered, the results of our regression analyses indicate that the shrinking of parental age differences that are attributable to delayed parenthood exhibit remarkable regularities across countries over time.

For all of the 15 analyzed countries, we found strong fertility postponement trends among both men and women. Our findings on fertility postponement patterns and on shifting parental age differences indicate that for women, later childbirth is associated with a smaller parental age difference; and, thus, with a more balanced power relationship. Over the last decades, we detected that younger mothers are having children with increasingly older partners, which suggests that they are increasingly likely to be in a union with unequal power relations. For fathers, later childbirth is associated with a larger parental age difference, which implies that they have greater power in the relationship. However, this effect has been decreasing over time as fertility postponement increased among both men and women.

As the mechanisms that underlie these remarkable regularities remain unclear, there are many opportunities for future research on parental age differences. The register data we used allowed for only limited additional analyses. However, restricting the analysis by parity for countries with parity information produced patterns similar to those reported here. 
Several different explanations for our findings are possible. The increasing age differences observed among young mothers could reflect rising economic uncertainties for young people that make family formation at early ages more difficult, especially for men. In some countries, these age differences might also reflect increases in the share of young mothers with migrant backgrounds; i.e., of mothers from countries where larger age differences between partners are more prevalent. In addition, as women's educational attainment and social status have increased, women are not only postponing union formation and parenthood, but are forming more age-homogenous partnerships. Among men, the observed downward shift in the intercept might be driven by higher levels of economic independence among women that enable them to partner with younger (and perhaps more genderegalitarian) men, or with men who are closer in age.

\section{References}

Blossfeld, Hans-Peter. 2009. "Educational Assortative Marriage in Comparative Perspective." Annual Review of Sociology 35(1):513-30. https://doi.org/10.1146/annurevsoc-070308-115913

Blossfeld, Hans-Peter and Sandra Buchholz. 2009. "Increasing Resource Inequality among Families in Modern Societies: The Mechanisms of Growing Educational Homogamy, Changes in the Division of Work in the Family and the Decline of the Male Breadwinner Model." Journal of Comparative Family Studies 40(4):603-16. https://doi.org/10.3138/jcfs.40.4.603

Billari, Francesco B. and Aart Liefbroer. 2010. "Towards a New Pattern of Transition to Adulthood?" Advances in Life Course Research 15(2-3): 59-75. https://doi.org/10.1016/j.alcr.2010.10.003

Dudel, Christian and Sebastian Klüsener. 2019a. "Male fertility data for 17 high-income countries Methods and data description." MPIDR Technical Report TR-2019-001. https://doi.org/10.4054/mpidr-tr-2019-001

Dudel, Christian and Sebastian Klüsener. 2019b. "Estimating men's fertility from vital registration data with missing values." Population Studies 73(3): 439-449. https://doi.org/10.1080/00324728.2018.1481992

Dudel, Christian and Sebastian Klüsener. 2019c. "New opportunities for comparative male fertility research: insights from a new data resource based on high-quality birth registers." MPIDR Working Paper WP-2019-023. https://doi.org/10.4054/mpidr-wp-2019-023 
Esteve, Albert, Clara Cortina, and Anna Cabré. 2009. "Long Term Trends in Marital Age Homogamy Patterns: Spain, 1922-2006." Population 64(1):173-201. https://doi.org/10.3917/pope.901.0173

Esteve, Albert, Joan García- Román, and Iñaki Permanyer. 2012. "The Gender- Gap Reversal in Education and Its Effect on Union Formation: The End of Hypergamy?" Population and Development Review 38(3):535-46. https://doi.org/10.1111/j.17284457.2012.00515.x

Fox, Jonathan, Sebastian Klüsener, and Mikko Myrskylä. 2018. "Is a positive relationship between fertility and economic development emerging at the sub-national regional level? Theoretical considerations and evidence from Europe." European Journal of Population 35(3): 487-518. https://doi.org/10.1007/s10680-018-9485-1

Goldscheider, Frances, Eva Bernhardt, and Trude Lappegård. 2015. "The Gender Revolution: A Framework for Understanding Changing Family and Demographic Behavior." Population and Development Review 41 (2): 207-239. https://doi.org/10.1111/j.1728-4457.2015.00045.x

Grow, André, Christine Schnor, and Jan Van Bavel. 2017. "The reversal of the gender gap in education and relative divorce risks: A matter of alternatives in partner choice?" Population Studies 71 (sup1): 15-34. https://doi.org/10.1080/00324728.2017.1371477

Jalovaara, Marika, Gerda Neyer, Gunnar Andersson, Johan Dahlberg, Lars Dommermuth, Peter Fallesen, and Trude Lappegård. 2018. "Education, Gender, and Cohort Fertility in the Nordic Countries." European Journal of Population 35(3): 563-586. doi: 10.1007/s10680018-9492-2. https://doi.org/10.1007/s10680-018-9492-2

Kalmijn, Matthijs. 2013. "The Educational Gradient in Marriage: A Comparison of 25 European Countries.” Demography 50(4):1-22. https://doi.org/10.1007/s13524-013-0229-x

Kohler, Hans-Peter, Francesco C. Billari, and José Antonio Ortega. 2002. "The emergence of lowest-low fertility in Europe during the 1990s." Population and Development Review 28 (4):641-680. https://doi.org/10.1111/j.1728-4457.2002.00641.x

Kolk, Martin. 2015. "Age Differences in Unions: Continuity and Divergence among Swedish Couples between 1932 and 2007." European Journal of Population 31(4):365-82. https://doi.org/10.1007/s10680-015-9339-z

Lesthaeghe, Ron. 2014. "The Second Demographic Transition: A Concise Overview of Its Development." Proceedings of the National Academy of Sciences 111(51):18112-15. https://doi.org/10.1073/pnas.1420441111 
Nitsche, Natalie, Anna Matysiak, Jan Van Bavel, and Daniele Vignoli. 2018. "Partners' Educational Pairings and Fertility across Europe." Demography 55(4):1195-232. https://doi.org/10.1007/s13524-018-0681-8

Presser, Harriet B. 1975. "Age Differences between Spouses: Trends, Patterns, and Social Implications.” American Behavioral Scientist 19(2):190-205. https://doi.org/10.1177/000276427501900205

Perelli-Harris, Brienna, Wendy Sigle-Rushton, Michaela Kreyenfeld, Trude Lappegård, Renske Keizer, and Caroline Berghammer. (2010) "The Educational Gradient of Childbearing within Cohabitation in Europe." Population and Development Review 36(4): 775-801. https://doi.org/10.1111/j.1728-4457.2010.00357.x

Pyke, Karen and Michele Adams. 2010. "What's Age Got to Do with It? A Case Study Analysis of Power and Gender in Husband-Older Marriages." Journal of Family Issues 31(6):748-77. https://doi.org/10.1177/0192513x09357897

Qian, Zhenchao and Daniel T. Lichter. 2007. "Social Boundaries and Marital Assimilation: Interpreting Trends in Racial and Ethnic Intermarriage." American Sociological Review 72(1): 68-94. https://doi.org/10.1177/000312240707200104

Skopek, Jan, Andreas Schmitz and Hans-Peter Blossfeld. 2011. "The Gendered Dynamics of Age Preferences: Empirical Evidence from Online Dating." Zeitschrift für Familienforschung 23(3): 267-90.

Sobotka, Tomáš. 2004. "Is lowest-low fertility in Europe explained by the postponement of childbearing?" Population and Development Review 30 (2): 195-220. https://doi.org/10.1111/j.1728-4457.2004.010_1.x

Van Poppel, Frans, Aart C Liefbroer, Jeroen K Vermunt and Wilma Smeenk. 2001. "Love, Necessity and Opportunity: Changing Patterns of Marital Age Homogamy in the Netherlands, 1850-1993." Population Studies 55(1):1-13. https://doi.org/10.1080/00324720127681 


\section{Appendix}

\section{Data preparation}

The data for all years and countries are taken from birth registers, and are complete enumerations, except for the first years of the U.S. data. Specifically, we use sampling weights to take into account that the U.S. data before 1972 are based on 50\% samples taken from the birth registers of U.S. states. From 1972 onwards, the data include complete birth registers from an increasing number of states; and from 1985 onwards, the full birth register data for all states are available.

Most registers cover all births of the resident population; except the registers for England and Wales, which include all births occurring in the corresponding territory. For some births, the father or the mother might be residing abroad: in the former case, the birth is likely not covered by the register; in the latter case, the data we have access to usually do not indicate that the information for the father relates to a person abroad. However, we expect that very few births are affected by this problem, and that the numbers of cases in which either the mother or the father is living abroad are likely to cancel each other out.

For Japan, the data available to us cover only marital births. The proportion of non-marital births in Japan is very low, at only around $2 \%$. Nevertheless, we added the missing births by age using data from the Human Fertility Database (2018). For details of this process, please see Dudel \& Klüsener (2019a). In Italy, births are registered at the municipality level using either a short form or a long form. While the long form is used in most cases, some small municipalities use the short form. The data we have access to only includes births registered using the long form. We dealt with this challenge by applying the same approach we used when faced with data limitations for Japan. Again, see Dudel \& Klüsener (2019a) for detailed descriptions of data handling.

For most countries, maternal and paternal ages above and below certain thresholds are not shown in the data, but are subsumed in open age intervals; e.g., births to mothers aged 49 and older are often assigned to the category " $49+$ ". Experimenting with categorizing ages in this way for countries for which we always know the correct age showed that the effect of the choice of the cutoff ages for these categories is negligible, as long as it is high enough. As using these open categories makes applying our imputation method easier (see below), we chose to use "15-" and "59+" as open categories for men, and "15-" and " $49+$ " for women, based on the assumption that fertility below age 15 and above age 49 (or 59) is very low. For instance, for fathers, the largest proportion of fathers aged 59+ across all countries and years studied was $0.2 \%$ in Italy in 1999, and was considerably lower for most other countries and years. 
For some countries, we only have access to age data that are already more restricted. This is the case for England and Wales (15-55 years for both men and women), France (17-46 years for both men and women), Germany (17-59 years for men; 16-45 years for women), Japan (17-59 years for men), and Sweden (15-50 years for both men and women). For all of the other countries, we can use the full age range of 15-59 years for men and of 15-49 years for women.

For most births, we know the age of the father and the age of the mother as single-year ages. The data for Sweden include information not on the parental age at childbirth, but on the age reached during the year. If, for example, a mother was 27 years old at the time of the birth, but turned 28 later in the same year, then her age is recorded as 28 years in the data. However, we do not expect this issue to affect the age differences between the parents, as it applies to both mothers and fathers.

In most country datasets, the age of the father is missing for some births, whereas the age of the mother is almost always known, except for a very small number of births. The reasons for these missing values are manifold, but for most countries and years, the proportions of missing values are low. Nevertheless, we decided to impute missing values. To impute missing paternal ages, we adopted the so-called conditional approach (Dudel \& Klüsener 2019b), which has been shown to perform well, especially when compared to competing approaches. Essentially, births with a missing paternal age are split up according to the age of the mother; e.g., all births with a missing paternal age and a mother aged 30 . For each maternal age, the distribution of the paternal age for births with no missing values is calculated; e.g., the paternal age distribution for births with a maternal age of 30. This distribution is then applied to births with missing values; for instance, births with a missing paternal age and a mother aged 30 are distributed across the paternal age range according to the paternal age distribution, conditional on the mother being 30 years old.

\section{General trends in parental age differences.}

Figure A shows trends in the mean age differences between the parents at childbirth in 15 countries, with the countries grouped by welfare state typology (Esping-Andersen 1990; Aspalter 2006); Figure B shows the underlying trends in the mean age at childbirth of mothers and fathers for all countries. When in Figure A we look at levels of mean age differences from a comparative perspective, no consistent pattern emerges. While the average age differences were generally between two and four years, no country group had consistent levels, and the heterogeneity across country groups was as large as it was within groups. For instance, for many years, Spain had a smaller mean age difference than Denmark; roughly at the level of the mean age difference in Sweden. Moreover, when we look at trends over time since the 1990s, we again see that no clear general pattern emerges, although some trends have been consistent within country group. In some countries, the 
mean age differences increased at least temporarily (Taiwan, Eastern Europe); while in others, they stayed constant or decreased (English-speaking countries, Denmark). But before the 1990s, there were also increases in the average age differences in the Englishspeaking countries analyzed. 
Figure A. Trends in the difference between mean paternal and mean maternal age at childbirth by country.
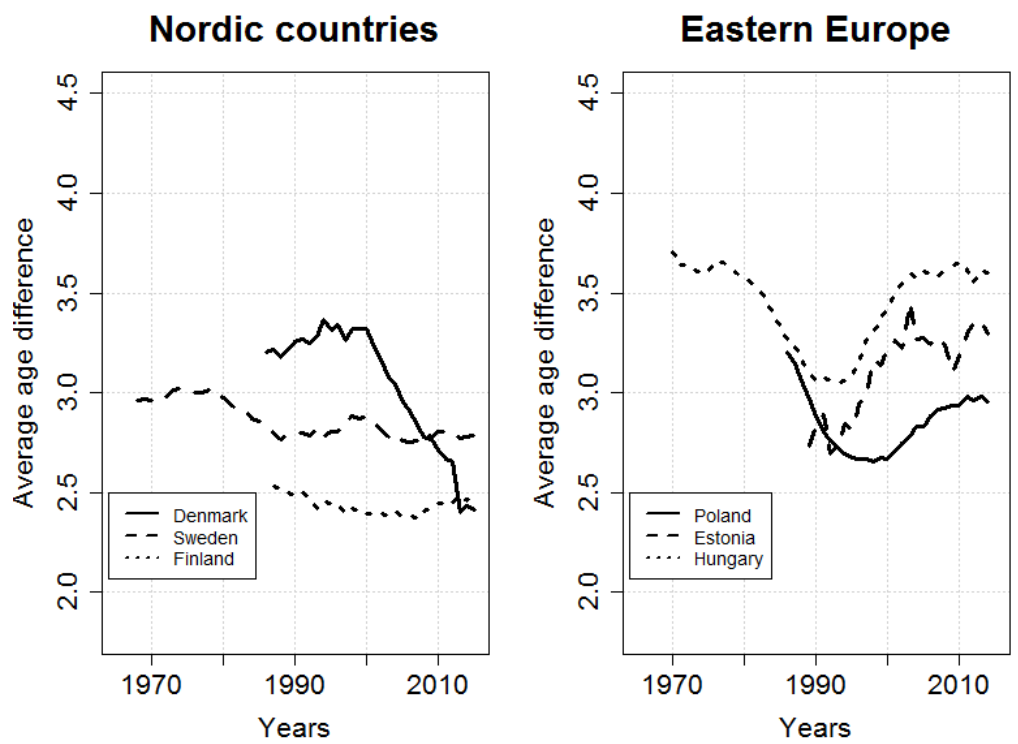

English-speaking countries
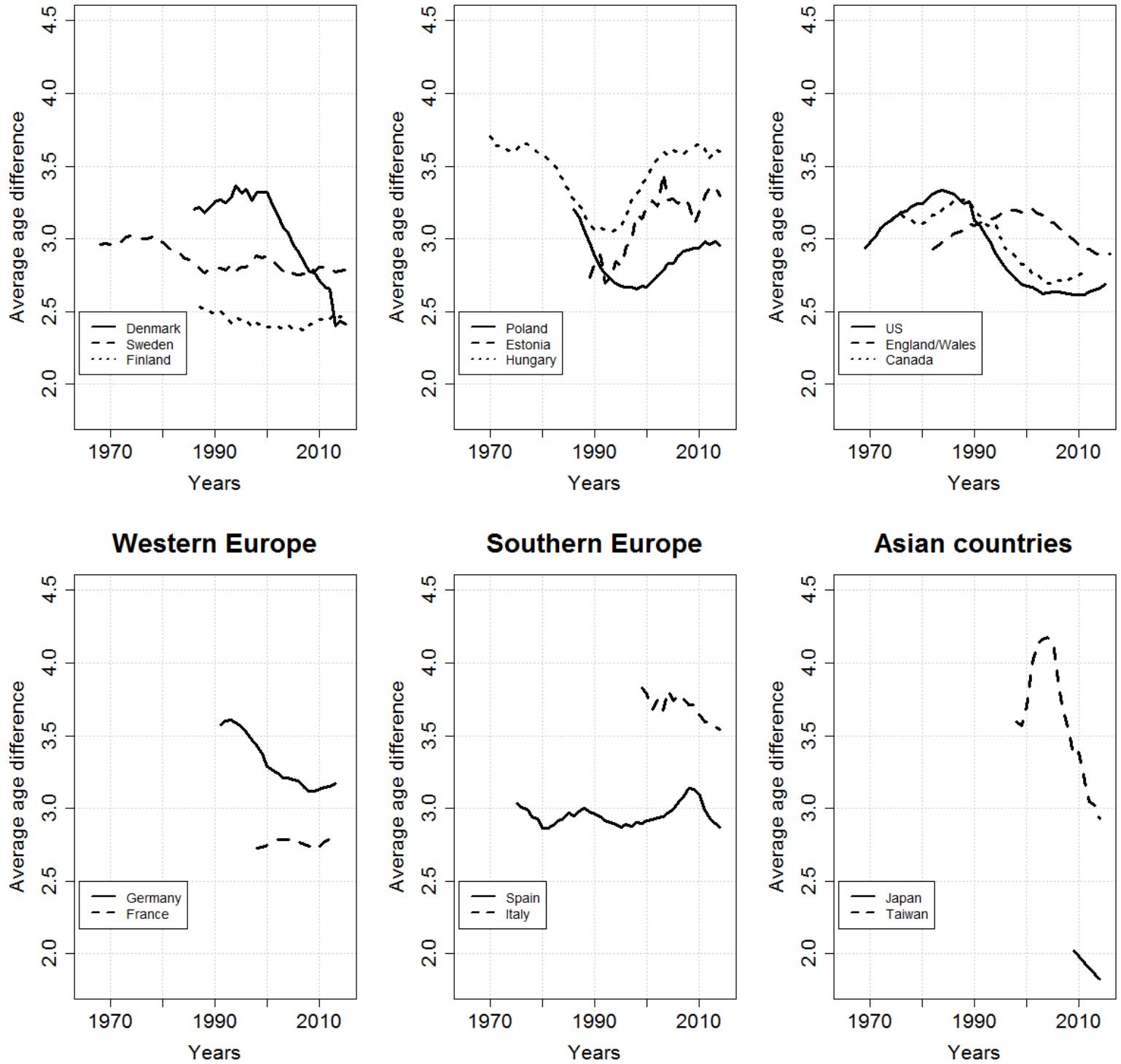

Source: Official Statistical Data, NBER (USA), own calculations 
Figure B: Trends in mean age at childbirth for men (dashed line) and women (solid line).
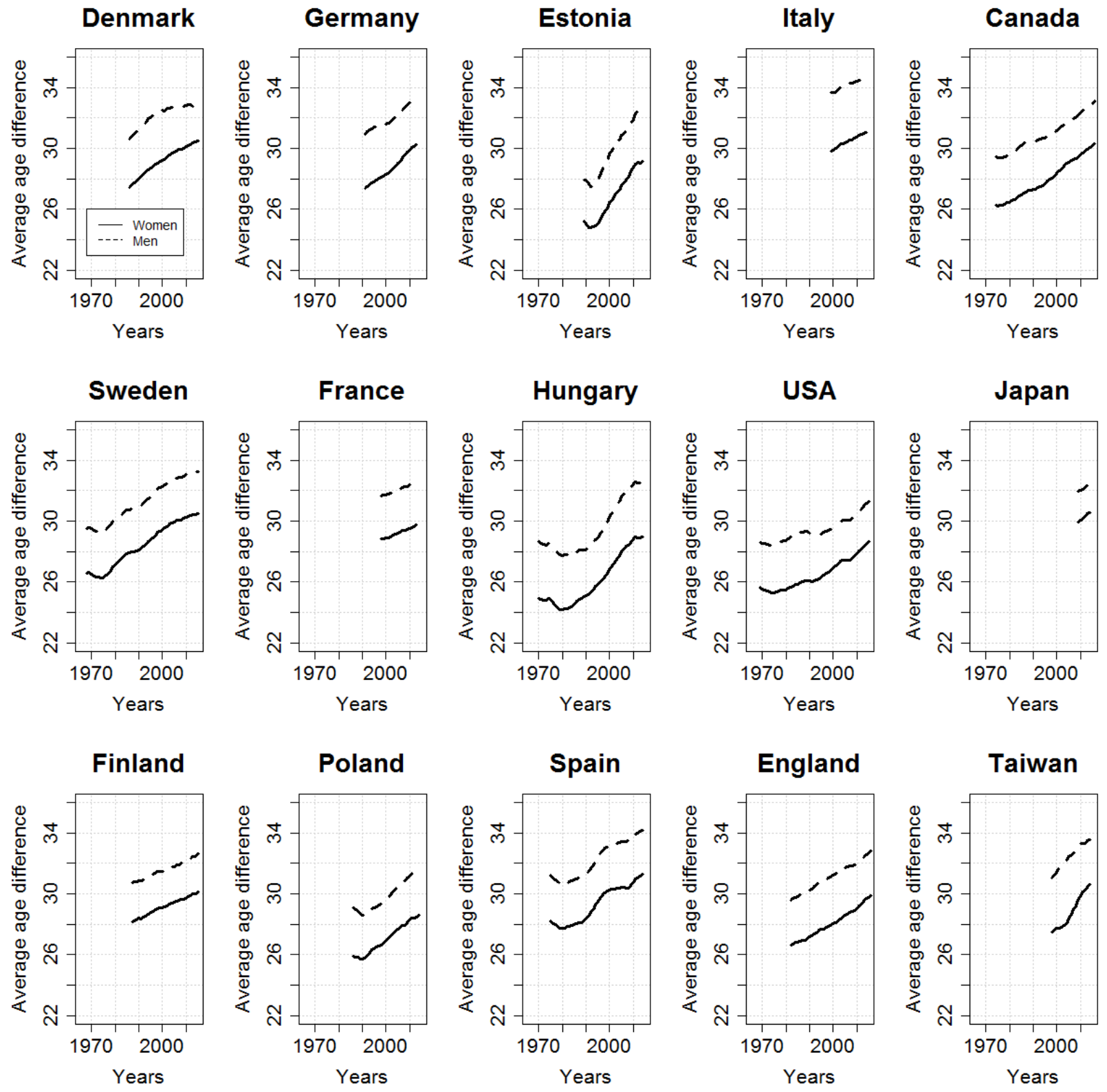

Source: Official Statistical Data, NBER (USA), own calculations 